\section{Reduced budget in prospect}

Geneva

BRITISH officials are beginning to sound out the 13 member states of CERN, the European Organisation for Nuclear Research near Geneva, to see if they would countenance a substantial reduction in the CERN budget (which amounts to some $£ 250$ million a year) while a fourteenth potential member, Portugal, has applied to join. Could Portugal pay for the reduction Britain requires? Certainly not, but the eagerness of Portugal and the dog-in-themanger attitude of Britain make a sharp contrast seen from CERN.

Even Britain's backing of salary increases at CERN (Nature 7 February, p.423) could be a ploy in the long run of reducing salaries; negotiations begin this year for a major two-year review of the

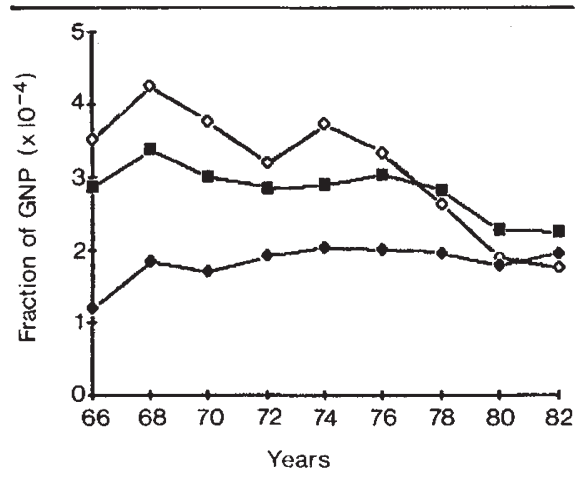

The decline of Britain's spending on high-energy physics (open diamonds) as a fraction of gross national product, compared with that of West Germany, France, Italy and the United Kingdom jointly (full squares) and Belgium, the Netherlands, Sweden and Switzerland (full diamonds). Salaries are included.

By 1982, UK spending was already below that of the latter "medium size" members of CERN.

CERN salary structure. Britain, it is said, did not wish to begin on the wrong foot from the start of these negotiations (which Britain will chair) by backing a sudden and unprepared French move to cut pay.

Thus Britain's head-counting looks ominous - particularly in the light of a committee chaired by molecular biologist Sir John Kendrew which will report soon on the value of Britain remaining a member of CERN. Sir John may praise the performance of CERN - it is, after all, at an alltime high in its history and even leading the world - but he may also criticize costs.

Britain's real spending on high-energy physics has been declining rapidly (see Figure), but European investment remains a third above that of the United States when measured as a fraction of gross national product. CERN argues that this reflects the superior quality of CERN accelerators, and that without this quality Europe would not be in such a commanding position. Fermilab in the United States is three years behind CERN in creating the antiproton-proton collisions that at CERN created the $\mathrm{W}$ and $\mathrm{Z}$ particles and now hint at supersymmetry. But British accountants may find the benefits imponderable.

CERN, however, says that their next big accelerator (the large electron-positron collider, LEP) is being built on constant budgets, so that cuts are already being made throughout CERN to pay for LEP's construction. The director-general, Professor Herwig Schopper, is cutting staff, and accepts a Thatcherite hypothesis that every organization has some fat to lose. "But we're now cutting to the bone", says research director Ian Butterworth.

The bone is research. Over the past five years CERN has run double the number of research hours of its most direct competitor, Fermilab, says CERN technical director Giorgio Brianti. "We run a good deal $-7,000$ hours a year, more than most nuclear power stations." But research after all is what investment in CERN is for.

Yet to cut running time, and hence electricity bills, might be the only real cut that CERN could now make. Already 70 per cent of the capital spending on LEP is committed. And salaries (half the CERN bill), while high by national standards, are low by international ones.

If running time were cut, physics would slow down, and competition from the United States would be more threatening.

Britain's possible complete departure from CERN is greeted with horror and disbelief in Geneva. CERN claims to have no contingency plans for the loss of Bri- tain's 17 per cent contribution, or its physicists, though there would be a year or two to act (the constitution requires withdrawal on the January after the January following announcement of withdrawal).

Carlo Rubbia, the Italian discoverer of the $\mathrm{W}$ and $\mathrm{Z}$ particles, says Britain should go if it wants to, and not hang about like the character in Verdi's opera Aida who sings "I'm going, I'm going" for five acts but never leaves. Bob Brown, a British physicist in one of the four giant experiments to be mounted on LEP, says Britain's leaving "is too awful to contemplate". His experiment, OPAL, in which Britain has a major contribution (the provision of a lead-glass scintillator) "would collapse" if Britain left. Another LEP experiment, DELPHI, might be threatened.

Others say Britain just could not spend effectively the $£ 50$ million that the Science and Engineering Research Council would be left with if Britain left CERN; and that the research students presently staying in Britain to do high-energy physics ( 80 per cent of them with first class degrees) would simply go to the United States, weakening British science. In the longer run, nonmembers do participate in CERN experiments, but they make triple the normal contribution to apparatus, and Britain's problem would not thereby be solved.

"It would be a disaster"' if Britain pulled out, said Schopper last week. "Would we throw out the British physicists? I cannot see that. But what would the other states say?". There would, in the end, be a limit to how long they would be willing to bail out a defaulter. Robert Walgate

\title{
No home yet for radiation source
}

THE European Synchrotron Source (ESRS), the 5-GeV light source that France and West Germany agreed should be built in France (in exchange for a supersonic wind tunnel to be built in Germany), is up for discussion yet again.

Now it is the turn of the Levaux Commission, the supposedly intergovernmental body set up by the European Science Foundation with the original aim of deciding the location of ESRS. France and West Germany effectively spurned the commission and decided among themselves (with British assistance) to put ESRS in France, hoping that the smaller states on the commission would agree.

But they did not; the situation was further complicated when the French government switched choices from Strasbourg (close to the German border) to Grenoble (in the French Alps), probably for electoral reasons. West German officials had always favoured Strasbourg, and were severely put out (though philosophical) when the French government changed its position.

Thus, when the Levaux Commission meets this week, French representatives will be all but isolated. France needs cash support to establish ESRS, and it is conceivable that strong pressure will be put on France to change its mind yet again. The regional elections feared by the French government, which could have displaced Louis Mermaz, the socialist president of the National Assembly, from his seat on the Grenoble regional assembly and perhaps precipitated a national election, are taking place last Sunday and next, so the internal political pressure will soon have changed. Not a stone has yet been turned for ESRS.

So could ESRS go to Strasbourg after all? Not if Denmark or Italy have their way, as Denmark still champions Ris $\varnothing$ and Italy Trieste. Scientific site visits to both places have taken place since France proclaimed the site would be Grenoble, and Italy continues to contest very loudly on behalf of Trieste. Last week, however, Italian physicists meeting in Trieste were talking of a compromise - the building of a $1.5 \mathrm{GeV}$ synchrotron radiation source to "complement" the $X$-radiation from the 5-GeV ESRS in the lower wavelengths (soft $\mathbf{X}$-rays and ultraviolet). Robert Walgate 